OPEN ACCESS

Edited by:

Juan Gilbert,

University of Florida, United States

Reviewed by:

Karina Liles,

Claflin University, United States

Curtis Cain,

Howard University, United States Manuel Perez-Quinones,

University of North Carolina at

Charlotte, United States

Edward Dillon,

Morgan State University,

United States

*Correspondence:

Zakiya S. Wilson-Kennedy

zwilson@/su.edu

Specialty section:

This article was submitted to

STEM Education,

a section of the journal

Frontiers in Education

Received: 01 March 2021 Accepted: 28 June 2021

Published: 08 July 2021

Citation:

Davis RD, Wilson-Kennedy ZS and Spivak D (2021) International Research

Experiences in the Development of

Minority Scientists.

Front. Educ. 6:674673.

doi: 10.3389/feduc.2021.674673

\section{International Research Experiences in the Development of Minority Scientists}

\author{
Raeshan D. Davis ${ }^{1,2}$, Zakiya S. Wilson-Kennedy ${ }^{2,3 *}$ and David Spivak ${ }^{3}$ \\ ${ }^{1}$ School of Education, Louisiana State University, Baton Rouge, LA, United States, ${ }^{2}$ College of Science Office of Diversity and \\ Inclusion, Louisiana State University, Baton Rouge, LA, United States, ${ }^{3}$ Department of Chemistry, Louisiana State University, \\ Baton Rouge, LA, United States
}

Undergraduate research and international experiences are often described as high-impact educational practices beneficial for undergraduate student success and for supporting the development of science identity and intercultural competencies. While several studies have investigated the impact of undergraduate research on students from minoritized groups, fewer studies have focused on their engagement in global experiences, and fewer still have explored their engagement in international research experiences. Drawing on the theoretical frameworks of Science Identity, Social Cognitive Career Theory, and the Intercultural Competence Model, this present study explores the benefits of participating in an international research experience for minority undergraduate scientists. Using a qualitative case study methodology, we examined the evolution of students' science identity, research competencies, and intercultural competence after engaging in a three-month international research opportunity in France and Belgium. We found that after participating in international research, minority undergraduate scientists had: 1) Increased confidence in their science identity and abilities; 2) Gained and strengthened skills necessary to be a successful researcher, 3) Recognized the influence of international exposure on their growth personally and professionally, 4) Expressed how monumental this research opportunity is for all minority students to experience. Our findings suggest substantial benefits from an international research experience on the development of minority undergraduate scientists.

Keywords: international research, science identity, intercultural competence and awareness, global experiences, minority scientists, underrepresented minorities, social cognitive career theory, high-impact educational practices

\section{INTRODUCTION}

Throughout the science, technology, engineering, and mathematics (STEM) workforce in the United States, there continues to be a disparity in the participation of underrepresented minorities collectively (National Science Foundation, 2019). White and Asian Americans have representation within the science and engineering (SandE) workforce at rates higher than their representation in the U.S. population. Conversely, African Americans, Latino/a Americans, Native Americans, Alaskan Natives, and Pacific Islanders have much less representation within the S\&E workforce than their representation in the U.S. population (Khan, 2020). This disparity in representation is often described as under-representation, and groups that are underrepresented as underrepresented minority or minoritized groups (URM) (Khan, 2020). Given the continued underrepresentation of these groups in 


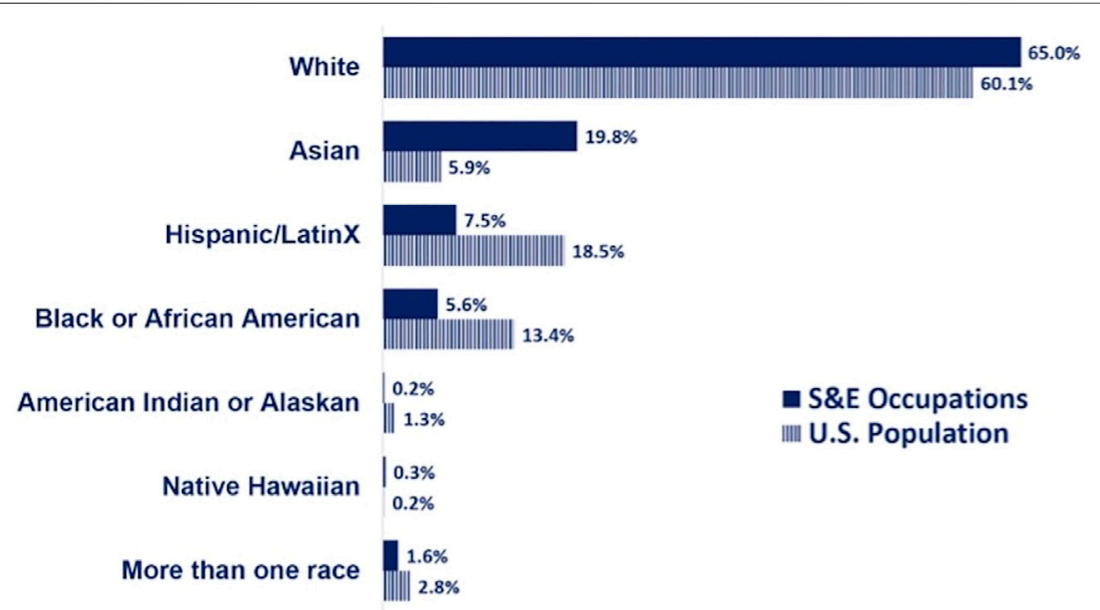

FIGURE 1 | Comparison of the Racial and Ethnic demographics of United States STEM Workforce and the U.S. Population.

the STEM workforce, i.e., $33 \%$ of the population vs. $13 \%$ of the STEM workforce (Figure 1), policymakers and educational leaders have focused on diverse approaches to address the cultivation of talent across all of our nation's citizenry.

\section{High-Impact Practices That Support Student Success: Undergraduate Research and International Experiences}

Within the higher education landscape, leaders have advocated for and adopted several practices that research has shown to be effective for improving student success. Often described as "highimpact practices," these efforts encompass first-year seminars and experiences, common intellectual experiences, learning communities, writing-intensive courses, collaborative assignments and projects, undergraduate research, diversity/ global learning, ePortfolios, service and community-based learning, internships, and capstone courses and projects (Kuh, 2008; Kuh et al., 2010).

Within the STEM disciplines at the undergraduate level, hands-on learning experiences through undergraduate research, communication or writing-intensive efforts, and internships have shown remarkable efficacy in promoting retention and success (Brownell and Swaner, 2010; DeLauder and Hollowell, 2012; Sanchez, 2012; Daniels et al., 2016; Haegar and Fresquez, 2016; National Academies of Sciences Engineering and Medicine (NASEM), 2016). As a high-impact educational practice for student retention and engagement, undergraduate research provides students with in-depth training beyond the classroom (Kuh, 2008). Specifically, engaging in undergraduate research has been proven to develop a student's self-efficacy, identity, and competencies as a researcher while exposing them to potential career pathways and graduate studies not previously considered (Egan et al., 2013; Pender et al., 2010; Russell, Hancock \& Mccullough, 2007). For students from groups historically underrepresented in STEM, undergraduate research opportunities can particularly prove beneficial in developing their identity, confidence, and sense of belonging in STEM despite the lack of representation (Bangera and Brownell, 2014; Carlone and Johnson, 2007; O’Donnell et al., 2015). Consequently, several studies have shown how URMs are impacted by engaged learning through undergraduate research and similar experiential learning with significantly positive effects (Wilson et al., 2012; Daniels et al., 2016; Fakayode et al., 2016; Haegar and Fresquez, 2016; Crawford et al., 2018; Davidson et al., 2018; Fakayode et al., 2018; Wilson-Kennedy et al., 2019).

International or global experiences, another high-impact practice, have reported several positive impacts on student success (Dwyer and Peters, 2004; DeGraaf et al., 2013; Engel, 2017). One such result is the increase in student engagement and persistence in their academic programs. For example, Camesano et al. (2016) discussed the value and importance of intentional incorporation of international experiences for Ph.D. students in Biomedical Engineering to enhance their experiences. Specifically, the program's goal was to offer students "a firsthand perspective on research and translation in a global context so that they are uniquely positioned to become successful leaders in an increasingly international market" ( $p .3)$. Students in this program shared how their growth personally and professionally resulted from participating in international experiences. While this program provided funding and resources for international exposure, not all students are afforded these opportunities built into their curriculum. Notably, many minority students never get the chance to travel abroad as a component of their academic studies. For example, minoritized groups who are underrepresented in STEM are also underrepresented in U.S. Study Abroad experiences (Figure 2), an indicator of domestic URM engagement in global experiences outside of the U.S. (Institute on International Education (IIE) and (U.S. Department of State's Bureau on Educational and Cultural Affairs, 2020). These groups have historically missed out on the types of experiences that advance intercultural competencies and leadership development. 


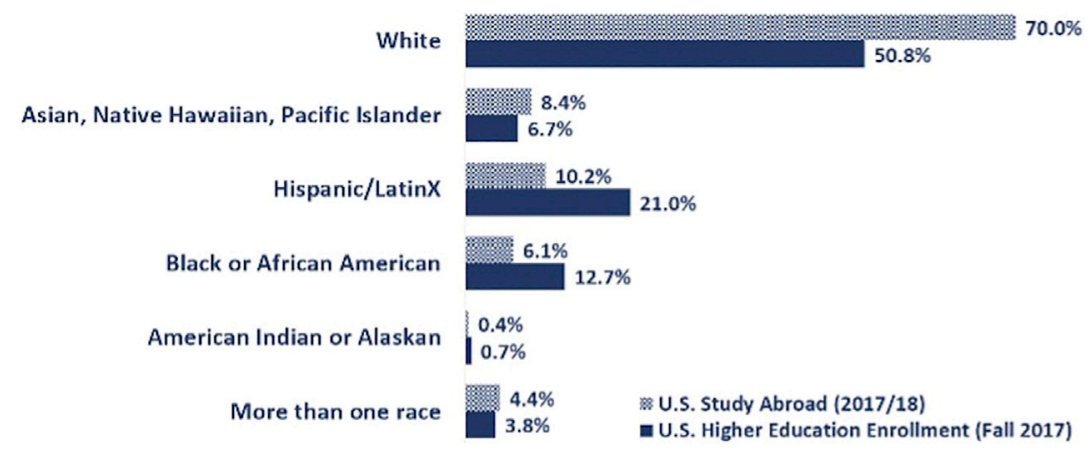

FIGURE 2 | Comparison of the Racial and Ethnic demographics of undergraduate students in U.S. Higher Education and those who have participated in U.S. Study Abroad.

Beyond having low participation by minority groups, international experiences have also been concentrated in nonSTEM disciplines. As an example, in 2000, natural science and engineering majors (life and physical sciences, engineering, agriculture, and health) comprised only $16.6 \%$ of the share of individuals participating in U.S. Study Abroad comparable to the Arts and Humanities, Languages, Business, and Entrepreneurial Leadership, and Social Sciences comprised almost 70\% of global experiences through U.S. Study Abroad. Consequently, for many years, international experiences for undergraduates have been under-utilized in the natural sciences and engineering disciplines, with very few students majoring in these fields having the opportunity to engage in even short-term immersive international experiences, much less any longer-term experiences. Notably, as the number of students participating in global experiences has grown, from 154,000 students in 2000 to 341,000 in 2017, so has the share of STEM students (Institute on International Education (IIE) and (U.S. Department of State's Bureau on Educational and Cultural Affairs, 2020). Nevertheless, we note that because of very rigid curricula, many STEM undergraduate programs do not provide the flexibility needed for a semester-long global experience.

Other norms in the STEM disciplines also limit access to global experiences. Arguably, the prominence of the U.S. STEM education and research enterprise has been a strong rationale for concentrating the academic and professional training of our citizenry within itself. However, the increased globalization of the S\&E workforce and enterprises has called into question this practice. Higher education leaders and others have sought to expand opportunities for undergraduates in STEM disciplines to engage in more global experiences that complement their technical research skills to include intercultural competencies needed for future leadership in the global S\&E enterprise and economy.

\section{International Undergraduate Research Experiences}

As higher education leaders and policymakers have grappled with strategies to increase STEM student access to and engagement in global experiences, one strategy that has gained traction is to combine global with undergraduate research. Several leaders have hypothesized that combining or layering high-impact practices may have potentially additive effects on student outcomes. Some studies have illustrated how layering high-impact practices result in positive outcomes for students (Finley and McNair, 2013). Accordingly, some faculty and academic leaders have posited that combining undergraduate research with global experiences delivered within an internship format could be an intriguing approach for preparing future leaders in STEM and supporting individuals for global STEM leadership (Duran et al., 2018).

Global undergraduate research experiences have the potential to be transformative for students with access to them. Within Higher Education and the STEM workforce, senior professionals actively engage in international research for collaboration and advancing innovation across borders within their respective STEM fields (Owens, 2018). However, few students are able to participate in international research during their undergraduate education. The significant financial commitment of such experiences and flexibility in the academic major are contributoring factors to access. To catalyze STEM student access and training in global experinces, the U.S. National Science Foundation (NSF) has taken a targeted approach by dedicating substantial funding to supporting the engagement of undergraduates in international research experiences. With this expansion of research offerings, undergraduate students are afforded a unique opportunity to engage in scholarly research pursuits and collaborations worldwide and broaden their perspectives of other countries and cultures. Moreover, international research experiences can significantly advance the professional, research, and technical skills of undergraduate researchers while exposing them to the world around them.

While extensive studies have investigated undergraduate research's impact on student development and retention, fewer studies have explored how these experiences in international research settings impact student learning and development (Green et al., 2008; McElmurry et al., 2003). Noting the limited exposure of STEM undergraduates to international experiences, URM in these disciplines are even more underrepresented than their peers in having global experiences. As we seek to understand how international 


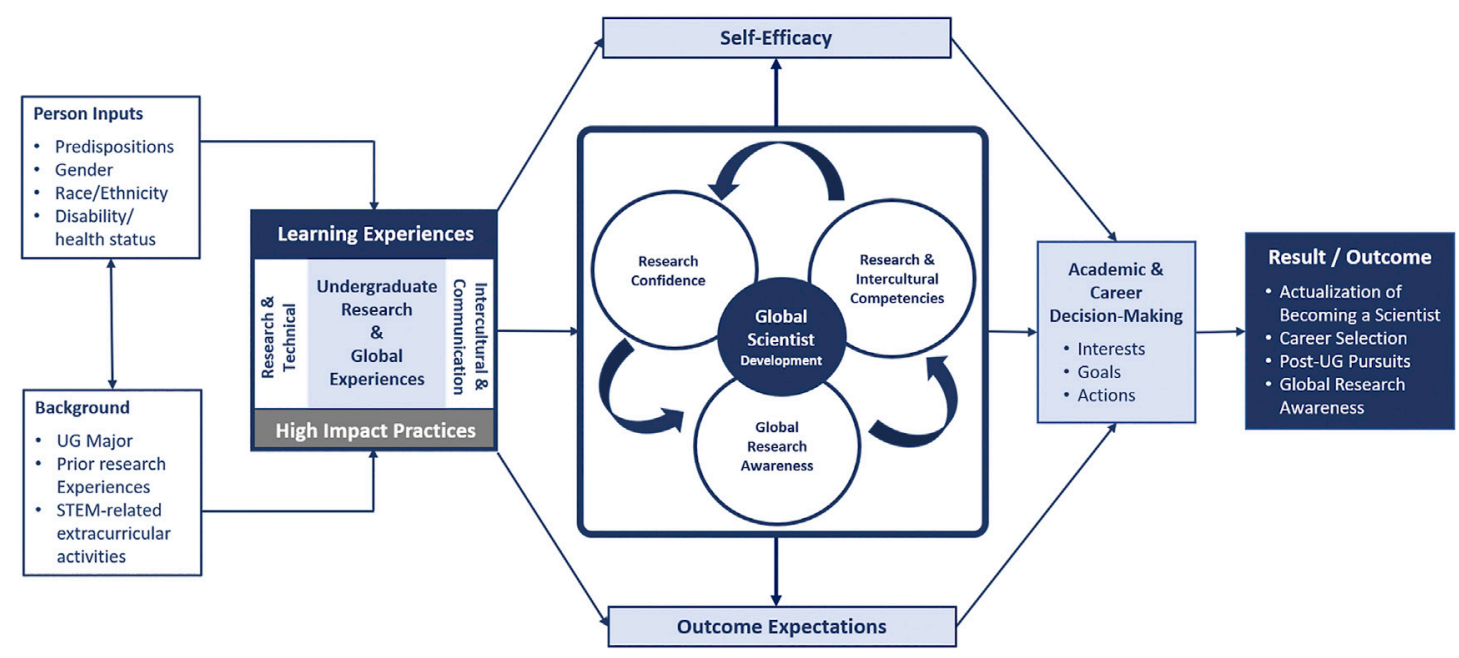

FIGURE 3 | A Conceptual Model Integrating Social Cognitive Career Theory, Science Identity, and Intercultural Competencies and Awareness to promote the development of undergraduates at Global Scientists.

research experiences impact those with access to these, it is imperative to include the impact of international undergraduate research on students from minoritized groups. Few studies have focused on URM engagement in global experiences, and fewer still have explored their engagement in international research experiences.

With this context in mind, this research study aims to explore the development of minority students' science abilities and confidence after participating in an international research experience. This study also explores how international research experiences developed participants' intercultural competence and awareness of global research and collaboration. This study has three guiding research questions:

1) How are international research experiences contributing to the educational experience of minority STEM undergraduates?

2) How do participants describe their growth in intercultural competence after living and working at an international research site?

3) How does minority students' participation in undergraduate international research programs support their actualization of being a scientist?

\section{CONCEPTUAL FRAMEWORK}

Fundamentally, this empirical study considers how two intersecting high-impact practices, i.e., undergraduate research and global experiences, impact URM STEM students and their actualization of becoming STEM professionals. Noting academic and professional training are critical components of a student's intent to pursue a career in a STEM career field, this research study is grounded in Social Cognitive Career Theory (SCCT) and incorporates Science Identity (SI) and Intercultural Competence Model (ICM) theoretical frameworks. As such, our study presents a conceptual model integrating these frameworks to promote the development of undergraduates as Global Scientists (Figure 3). This model will investigate minority students' perceptions of the impact of international research experiences on the ideation of becoming a scientist, research confidence, and intercultural awareness. We hypothesize that these factors are essential to URMs actualizing goals of a STEM career.

Social Cognitive Career Theory forms the foundation of our conceptual framework. Developed by Lent et al. (1994), SCCT posits that individuals approach career development in three interrelated aspects: 1) self-efficacy, 2) outcomes, and 3) personal goals. Thus, individuals who believe or have confidence in their abilities to reach a favorable outcome are likely to pursue opportunities to achieve their goals. Consequently, SCCT illustrates the impact of affirmational growth opportunities. As students meet with challenges (or goals) that they achieve, they develop confidence (self-efficacy) in their ability to do well (via outcomes) in future challenges (goals). Even if each outcome is not ideal, if the students are learning and adapting through the process, they can develop confidence in their abilities to achieve their goals. Notably, the model considers the impact of one's identity on their educational and career development process.

By adapting the SCCT framework for understanding STEM career development, Byars-Winston et al. (2016) introduced the Modified model of SCCT incorporating Science Identity theory to offer a scientific approach to understand the development of academic and career goals for underrepresented minority groups in STEM. Previous research studies have indicated that the success in one's research experiences and future research careers is significantly predicated on their research related selfefficacy (Hurtado et al., 2009; Chemers et al., 2011; ByarsWinston, 2015).

Central to the modified SCCT model are the elements of Science Identity (Carlone and Johnson, 2007), which describes the three interrelated factors that comprise a student's science identity: competence (ascertaining and understanding scientific 
knowledge), performance (demonstration of scientific knowledge to an audience), and recognition (acknowledgment as a scientist by self and others). For underrepresented minorities in STEM, science identity is a significant factor in developing their academic and career goals (Carlone and Johnson, 2007; ByarsWinston et al., 2016). Simply put, minority students must have the knowledge (know-how) to be able to perform, perceive themselves as scientists, and have confidence that others perceive them as scientists to attain success within their desired STEM careers.

Our conceptual model is also informed by Deardorff s process model of Intercultural Competence (Deardorff, 2006; Deardorff, 2009). While the application of this framework is concentrated on short-term cultural immersion experiences, studies have reported notable success in the development of intercultural competence and global engagement among participants in an intentional cultural experience (Salisbury et al., 2013; Stebleton et al., 2013; Murphy et al., 2014). For context, the foundation of this model are five corresponding elements to cultivate growth in intercultural competence: attitudes (respect, openness, curiosity, and discovery), knowledge (cultural self-awareness and deep cultural knowledge), skills (listening, observing, interpreting, and relating), internal outcomes (adaptability, flexibility, and empathy), and external outcomes (effective and appropriate communication and behavior in an intercultural situation). As noted, intercultural competence development is an on-going process throughout one's life. Thus, each participant's understanding and development in this area varies at different points of the process. Consequently, our study focused on the internal and external outcomes of our participants in the laboratory and in society. Also, we explored how their orientation in an intercultural research setting heightened their awareness and understanding of science and research on a global scale.

To account for the layered effects of undergraduate research and international experiences, our conceptual framework posits an interplay of the three spheres, 1) Research Confidence, 2) Research and Intercultural Competencies, and 3) Global Research Awareness, as the foundation of minorities development in the total scheme of global scientist development. We theorize that the integration of these three spheres coupled with one's self-efficacy and outcome expectations is supported by their learning experiences. As such, these elements are essential components in developing an undergraduate's scientific interests, goals, and actions. Moreover, their participation in such experiences leads to actualization of becoming or being a scientist, career selection, post-undergraduate pursuits, and global research awareness.

\section{METHODS}

To explore the research questions for this study, a qualitative research design was employed to allow for an in-depth, rich exploration of the unique experiences of the participants. Noting the small numbers of minority students engaging in international research experiences, a qualitative study can provide an empirical research approach to deepen our understanding of this critical population and their lived experience within and beyond their engagement in international research as an undergraduate. A single case study approach was employed to gain a comprehensive understanding of complex issues, topics, or problems within their real-world context (Merriam and Tisdell, 2015; Stake 1995; Yin, 2017). As prescribed by (Yin 2014; Yin 2017), case study research explores a real-life, bounded system (case) through multiple forms of data. For this study, the bounded case explored the experiences of undergraduate science researchers who participated in the France-Belgium International Research Experience for Undergraduates (iREU); most of the undergraduate research participants are minority students recruited through the Louis Stokes Alliance for Minority Participation in Science, Technology, Engineering, and Mathematics (LSAMP) Program (National Science Foundation, 2020). Because Louisiana State University is the home site for this international research program, IRB approval (IRBAM-20-058801) was granted from this institution to conduct research.

As mentioned, the focus of this research study was the iREU program hosted in France and Belgium. For each research experience, the student researcher identified a researcher at the international site with similar research interests and availability to mentor them during their program tenure. None of the participants had a relationship with their research mentor before the start of their program. Another notable characteristic of the research setting is the language differences in the professional and social environments. In the research lab, the standard language is English which did not pose any challenges as all of the students were native English speakers. However, the students did encounter language barriers in the social settings as the primary language is French.

\section{Participants}

The general population of interest for the study was science majors who participated in the France-Belgium iREU program during their undergraduate academic careers. Given this iREU program's selective nature, we employed a convenience sampling method for participation in this study. Thus, participation in this study was open to all former iREU participants. Using the iREU program contact list, the former iREU participants were contacted via email to garner their interest and complete an initial demographic survey. By design with intentionality, a high number of these iREU participants were recruited from LSAMP programs in U.S. Colleges and Universities. From the initial survey, the participants were contacted via email to confirm their interest and schedule a virtual interview. All participants of this study participated in at least one summer in the international research program prior to Summer 2020 and were interviewed for this study in the latter months of 2020 . The study's participants included eight 8) students. The participants included five 5) women and three 3) men. All of the participants were active LSAMP members at the time of their participation in the iREU. The majority of the participants identified as a member of a racial or ethnic minority; one participant identified as White. All of the participants engaged in STEM-related extracurricular activities, including 
TABLE 1 | Participants' profiles.

\begin{tabular}{|c|c|c|c|c|c|}
\hline Pseudonym & Gender & Race/Ethnicity & Undergraduate major & $\begin{array}{l}\text { Undergraduate institution } \\
\text { profile }\end{array}$ & $\begin{array}{l}\text { Post-undergraduate } \\
\text { pursuits }\end{array}$ \\
\hline Emily & Woman & $\begin{array}{l}\text { Mexican/Indigenous } \\
\text { ancestry }\end{array}$ & Biology & Large, public, state university & Masters of science in biology \\
\hline Jacob & Man & Black/Native american & Chemistry & $\begin{array}{l}\text { Medium, public, state historically black college/ } \\
\text { University (HBCU) }\end{array}$ & Chemistry Ph.D. program \\
\hline James & Man & White & Marine science & Medium, public, state university & Inorganic chemistry Ph.D. program \\
\hline John & Man & Latino & Chemistry and physics & Medium, public, state university & $\begin{array}{l}\text { Post-baccalaureate research } \\
\text { scholar }\end{array}$ \\
\hline Mary & Woman & Native american & Chemistry & Small, public, regional university & Graduating senior \\
\hline Natasha & Woman & $\begin{array}{l}\text { Black/African } \\
\text { american }\end{array}$ & Biochemical engineering & Large, public, land-grant university & $\begin{array}{l}\text { Biochemical engineering Ph.D. } \\
\text { program }\end{array}$ \\
\hline Rosa & Woman & Latina & $\begin{array}{l}\text { Cellular and molecular } \\
\text { biochemistry }\end{array}$ & $\begin{array}{l}\text { Large, public, state hispanic serving } \\
\text { institution (HSI) }\end{array}$ & Biosciences Ph.D. program \\
\hline Taylor & Woman & Latina & Materials chemistry & Medium, public, state university & $\begin{array}{l}\text { Materials science \& engineering } \\
\text { Ph.D. program }\end{array}$ \\
\hline
\end{tabular}

undergraduate research prior to the iREU. Six of the participants were enrolled in graduate programs at the time of the interview. The remaining two participants were in the process of applying for graduate programs; one participant was employed as a postbaccalaureate research associate, and the other participant was a graduating senior. Each of the participants provided their own pseudonyms, which ensured their identity remained confidential (Table 1); these pseudonyms will be used in the discussion of study findings.

\section{Data Collection and Analysis}

As prescribed by the case study approach, we collected multiple forms of data, inclusive of documents and interviews (Stake, 1995; Yin, 2017). The primary mode of data collection was one-on-one semi-structured interviews that lasted approximately $30 \mathrm{~min}$ to $1 \mathrm{~h}$. All of the interviews were conducted virtually using the Zoom platform and were recorded. The interview protocol included questions about the selection of their undergraduate degree path, current career and education path, iREU program experience, perspective on global research, and a reflection of their growth in research abilities and intercultural competence. The interview protocol utilized can be found in the Supplementary Material. The research team also analyzed the iREU program's grant, iREU year-end reports, promotional materials, and the LSAMP-NSF website to gain a better understanding of the organization's mission and context.

For the data analysis, each interview audio was transcribed verbatim using Rev transcription services. Once transcribed, each transcript was read thoroughly to gain an understanding of each participant in the study (Yin, 2017). Next, each transcript was uploaded in Dedoose qualitative coding software. Initially, each transcript was open-coded producing subcategories to develop a preliminary codebook. Each transcript underwent several rounds of axial coding, and connections were made between the subcategories to establish the major codes (Strauss and Corbin, 1998). Throughout the analysis, multiple data sources were actively examined to develop an in-depth understanding of each case individually in relation to the research questions (Yin 2014; Yin 2017). The final codebook consisted of 16 major categories. Once the codebook was finalized, the thematic analysis process began by categorizing codes by research questions. Next, emerging ideas were developed using the codebook and excerpts. The emerging ideas process interprets the data by using thoughts verbatim from participants or paraphrasing the comments from participants. Once completed, the emerging ideas were grouped by relationships to determine the final themes of the research study. Each step of the data analysis was documented individually to ensure trustworthiness. Throughout the data analysis process, there were several strategies of trustworthiness employed (Lincoln and Guba, 1985). The researchers employed member checking and peer-debriefing throughout the coding process to make sure the data was trustworthy. Once the study findings were completed, participants were asked to review the findings to ensure the trustworthiness of the results (Miles and Huberman, 1994).

\section{Positionality Statement}

The research team included two faculty members and one doctoral candidate, whose research interests and professional responsibilities focus on Science and Undergraduate Research and has various experiences with the undergraduate science opportunities and the LSAMP program. The first author is a doctoral candidate and graduate researcher for the College of Science at a PWI. With a science educational background, her research agenda focuses on the experiences of historically underrepresented students in science programs. Her goal is to advocate for equitable academic opportunities for the retention and success of these student populations through her research. The corresponding author is a research faculty member in chemical education and an administrator within the College of Science at a PWI. As a leader on almost $\$ 30$ million in extramural support from NSF, NIH, USDoEd, and philanthropic agencies, she has designed and implemented over 20 education projects, which have employed mentoring models to create and test development structures that cultivate self-efficacy and agency, particularly for groups historically underrepresented in STEM. Her research centers on studies of the persistence of individuals from all backgrounds in STEM higher education and careers, with 
a primary focus on faculty and student recruitment, retention, and success. The third author is a professor in the Department of Chemistry at a PWI for 22 years. In addition to his research program in polymer chemistry, he is currently the Principal Investigator for the NSF-funded International Research Experiences for Undergraduates that has sponsored over 80 students in a mentored research program in France and Belgium over the last nine years.

\section{RESULTS}

The data analysis revealed four salient themes that emerged across the eight participants. We found that after participating in international research, minority undergraduate scientists: 1) Increased confidence in their science identity, knowledge, and abilities; 2) Gained and strengthen skills necessary to be a successful researcher, 3) Recognized the influence of international exposure on their growth personally and professionally, and 4) Expressed how monumental this research opportunity is for all minority students to experience.

\section{Theme 1: Increased Confidence in Their Science Identity, Knowledge, and Abilities}

Throughout the interviews, participants shared how this international research experience helped them validate their sense of belonging and actualize their future in STEM. All participants were asked to rank their science confidence and competencies on a 10 -point scale as a researcher before the iREU. The responses ranged from three to eight, with most of the participants citing their lack of confidence and competencies as the reason. Specifically prior to the iREU, Taylor shared:

I will be $100 \%$ honest with you. I put off that I'm confident because in my specific major, there were eight of us, and I was the only woman, and the rest are White men. Then, the overall major has 32 of us, and I think three of us are women, and the other two were White. A lot of them were involved in research, and I looked down at myself very much as being part of the lower end of the spectrum. So, I ranked myself very low. Not only in my research, but I think just overall in my academic field. I believed that I can't be anything that special, but I tried to put off that confident front of I know it, but at least I'm embracing it.

Like Taylor, many of the participants struggled with their confidence and identity as a researcher. Upon reflection of the iREU experience, all participants were asked to rank their science confidence and abilities again on a 10-point scale as a researcher after the iREU. The responses ranged from six to ten, with most participants describing considerable growth in their confidence and competencies. After reflecting on her iREU experience in France, Rosa shared, "I would say now a 10. I feel more confident that no matter where I go, I'll be able to get the hang of it. Now, I know that even with the language barrier and the different culture, I can make it." The other participants shared similar sentiments of confidence and assurance in their science identity and competencies.

Additionally, most participants shared how this iREU experience affirmed and validated their sense of belonging and confirmed their pathway in STEM. Natasha passionately shared:

I think France really just taught me it's okay to love what you love. I look at all these other people that love what they love and just seeing them speak at seminars. We had like weekly seminars, and I had to present at once. It was just like, wow, here I am. A black girl from the States, you know ... I've had people tell me that you bring your full self, and frankly, I'm like, who else am I supposed to be? Like the white doctors? I'm not white. I'm black. I mean, I have personality, and I'm in STEM, you know. We exist. So I'm not about putting myself in a box. France taught me, be yourself.

Like Natasha, most of the participants returned home from the iREU affirmed in their sense of belonging and also with direction for their research interests and post-undergraduate pursuits. James shared, "I saw this as a pretty good long-term job prospect. This is research I find interesting, and this is research I want to do. It also prepares me for a potential future in industry because energy storage is not going away anytime soon."

Lastly, participants expressed how the positive feedback from their faculty mentors and research advisors bolstered their confidence and science identity after participating in the iREU. Whether through verbal affirmations or an increase in autonomy in the lab, all participants shared positive accounts of their faculty mentors and research advisors' response to their growth after participating in the iREU. Specifically, Jacob shared:

It's reaffirming as well ... I think they're even more blown away because I talked to my professor in France, and we recently published a JACS Publication. I told him, and he was like "I can't even imagine publishing for JACS, and you're already publishing there already," which is crazy. It's just being able to share those experiences with them. They definitely treat me as a colleague, basically, like someone who actually knows the research that they're talking about.

\section{Theme 2: Gained and Strengthened Skills Necessary to Be a Successful Researcher}

Given the immersive nature of this research experience, all of the participants described substantial improvement in their research, technical and professional skills. Both Jacob, James, and John shared how their technical skills developed with conducting large-scale experiments. Specifically, John shared:

One thing I learned was to work with large-scale reactions. I did reactions at my home institution in 
the milligram scales. It was very small. In France, I had to work with reactions that require $10 \mathrm{mg}$ or $10 \mathrm{~g}$ of this ... I gained a lot of confidence in working in the glove box for anaerobic reactions. It gave me a lot of confidence in working in that kind of environment.

Not only did participants gain new skills, but some also shared how they developed protocols and taught other researchers in their lab. Natasha recounted her experience teaching her lab mates how to perform a bacteria culture for the first time. She enthusiastically explained:

And I was like, "Whoa. Girl, you're so capable. Look at you". I taught them how do the bacteria culture. They had not conducted one before in that lab. I helped them order the strains, learn how to do the culturing, and use the materials. I taught the whole protocol for conducting the experiment.

In addition to in-lab skills development, most participants shared how their professional skills, such as oral and written presentation of their research, improved. Specifically, Jacob shared

I think that was one of the major things that opened my eyes on what does it mean to be a scientist. It's not just having the confidence to step into the lab. It's really having that follow through and being able to write about something to unknown audience. You are writing about your research, and you don't know who's going to be the reviewer. You don't know if someone's going to be an expert in the field, or if they're going to be tangentially related to it. I definitely learned that science has a lot more to do with writing than I had originally thought ... That's when I understood the skill sets of a scientist. It's not just lab and understanding the science. It's really having this academic voice. Can you convince people that you know what you know? ... I had to also present poster presentations, but it was really giving talks and group meetings, where I learned more appropriate ways to present your work. It's something I never really had too much of that experience before.

Like Jacob, several of the participants shared how their communication skills as a researcher strengthened to be able to discuss their research with a wide variety of audiences. James shared, "I think it was the general science communication, I got a lot more comfortable with it. I got a lot more comfortable with just talking about the work I was doing, but in a more casual format".

Among their skills development, all of the participants spoke to the development of their work-life balance adopted from their experience with this specific iREU. Specifically, Rosa shared:

I am accustomed to Latino-Hispanic culture, and White people as well ... For me, here in the U.S. it's like no holidays, you have to work mentality. Over in France, it's like, we don't have to come on weekends, or you don't have to stay after five or six. I was not accustomed used to that. I was accustomed to working all day, every week. In France, they taught me that balance. It also showed me that if you focus really on what you need to do, you can be really proficient. You don't need to stay all day long in the lab to get the data that you need to get really good results.

As participants reflected on the work ethic and culture in France and Belgium, Emily summed it up perfectly: "I work to live. I don't work to work or live to work". In contrast to their fast-paced research experiences in the United States, all of the participants shared how their experience in the FranceBelgium iREU encouraged them to foster a healthy worklife balance for their STEM careers. For Natasha, she shared, "I think what's helped me for grad school now is learning that work-life balance. In college, I feel like with STEM majors, we get caught up in getting work done, grades, everything. But in France, And I tell you, well, the whole E.U. cares about your health and your family.

\section{Theme 3: Recognized the Influence of International Exposure on Their Growth Personally and Professionally}

For many of the participants, this international research experience broadened their understanding and awareness of research collaborator relationships across countries. Participants remarked how imperative it is to have international research collaboration in the advancement of STEM to solve world issues. Specifically, Mary shared:

It gives you a broader worldview. It's easy to get stuck in your research lab. You do know that other people are doing the same thing that you're doing, not literally but metaphorically in a lab, all over the country, all over the world. However, to physically go to a different lab in a different country, it really drives the point home. Given this recent pandemic, that's one thing that keeps harking back to my mind. People all over the globe are working on these vaccines. People from all different walks of life, all different educational levels are coming together to work on something. I think that's the beautiful thing about Chemistry.

Similar to Mary, Emily shared how international collaborative research expanded her perspective of science and enlightened her to the necessity for diverse backgrounds and perspectives in science. She explained:

Science involves a lot of people, and everyone needs everyone. Everyone has a part to play, and your background plays a part. I feel like bringing a lot of people from a lot of different countries, you have different perspectives. You have different backgrounds and ways of thinking of new questions. I definitely feel like collaboration and working in 
different labs in different countries definitely expands how we do science in general.

Not only did their perspective on global research and international collaboration evolve, but several of the participants shared how they have been able to establish their own research collaboration teams. Specifically, Taylor shared, "I'm in the process of working to publish a paper with some of my collaborators from France ... I think that really put it into perspective for me when I went abroad that as a scientist I can not only just contribute to the immediate field, but to the larger field, and different ways that could I do that". Similarly, Natasha's research mentor encouraged her to develop international collaborations during her time in France. She shared

$\mathrm{He}$ was like, "We are not publishing enough internationally, with co-authors from different countries. Yeah, we're good at collaborating in the U.S. but we could improve international collaborations." And I think that's something I took from the experience. We have all these resources. I don't believe in reinventing the wheel because someone's done something or part of what you want to do somewhere. Figure it out, email them, get a conversation going".

In addition to their growth professionally, participants discussed how engaging with individuals from different countries and cultures expanded their personal views on various topics. James recounted his experience discussing politics with colleagues during the U.S. 2016 election. Specifically, he shared:

While I was there, we had the 2016 primary election and then the 2016 general election. I got exposed to that from a very outside perspective. It was really interesting seeing how different the culture there was around just discussing politics. It was a very comfortable topic to chat about. The thing that I found really refreshing was that the culture around that was that it was okay to talk about things and have different opinions, in a way that it's not in the U.S.

Similar to James, Jacob reflected on his conversations discussing the similarities and differences in race relations in U.S. and France. Specifically, he shared, "In America, of course, a lot of people understand what it means to have these minority programs or what affirmative action looks like, or a lot of these terminologies are thrown around that a lot of Americans understand. But people in France, they had no idea what I was talking about".

\section{Theme 4: Expressed How Monumental This Experience is for all Minority Students to Partake in}

After reflecting on this international research experience, all of the participants resoundingly expressed how this opportunity affirmed the trajectory of their lives as scientists. As Taylor reflected on the iREU experience, she expressed the gravity of this opportunity in hindsight. She shared, "I didn't realize it either at the time, the gravity of the opportunity that we were being given. I don't think I realized it until I went home ... this is not an everyday thing, and this is something so out of left field that so many students don't get the opportunity to do it. I think I would have maybe appreciated it more in the beginning to understand that". Similar to Taylor, several participants shared how grateful they were for the opportunity. James summed up their sentiments perfectly, "It definitely changed my path forward. It really helped me to define what I want to do and where I'm at now. I absolutely would not be here right now if I hadn't done that program. I'm really, really grateful for that".

In addition to their gratitude for this international research opportunity, participants expressed how the LSAMP program has been integral in their science success. Taylor shared, "It's not that you need the help, it's that these people want to help you because they see something in you that you're capable of doing it." Similar to Taylor, Rosa shared how LSAMP provides an allencompassing support system for those who participate. Specifically, she said, "I think it's a complete package because here, the people from LSAMP really supports you, not only at the professional level, but also, at the personal level ... no matter the situation, you know they have your back, because there's a constant personal communication all the time".

Given the significance of this iREU on their overall development as scientists, all of the participants exclaimed how monumental this opportunity would be for all minority students to experience. Natasha passionately shared, "I'm very grateful for this experience. I will brag about France to the mountaintops. People would probably get annoyed by it, but I want to tell it so that little girls can know that they can go to France, too, and do research". Similar to Natasha, Jacob enthusiastically expressed "that this experience is the linchpin that says, "You're not bound here. You can succeed outside, you can succeed in any environment, basically. I think it's really just that experience I took from there. I left France a more confident person in terms of just all aspects of life. I think that's really what that IREU trip means to me".

\section{DISCUSSION}

Previous studies on undergraduate research generally focused only on U.S.-based research experiences for all science students. Conversely, little is known about the benefits of international research experiences on the science development of minority students. Thus, our study focused on exploring the development of science identity and competencies in minority undergraduate scientists after participating in an international research experience. The three research questions in this study sought to illuminate the perceived benefits of iREUs through our eight participants' experiences. Although each participant had a highly individualized research experience, there were similar mutual benefits gained from their participation in the iREU. 
Firstly, our findings answered the first research question by presenting detailed insights on the value of international research to minority STEM undergraduates' educational experience. Aligned with prior literature on undergraduate research, we too found that our participants experienced substantial development in their research confidence and competencies. While each participant's individual research experience was unique, most of them attributed the increase in autonomy, responsibility, and exposure to new techniques for their growth in confidence and competencies. Aligned with our conceptual framework, our findings corroborate the substantial contribution of iREUs to our participant's research self-efficacy and science identity development. Thus, our participants spoke extensively about their affirmed sense of belonging and direction for their post-undergraduate endeavors and STEM careers. At the time of their interview, six of the participants were enrolled in graduate programs and actively conducting research. The remaining two participants were in the application process to their desired STEM graduate program. Therefore, we concur that international research experiences can contribute substantially to the research self-efficacy, confidence, and competencies development of undergraduate students.

Secondly, unlike previous studies on undergraduate research, our research study explored the benefits of research at an international site for U.S. students for a minimum of three 3 ) months. Most of the previous literature on international exposure focuses on short-immersion experiences, like study abroad, for students. Thus, an experience of this length and magnitude presents increased opportunities for developing intercultural competence and awareness in participants. Our findings answered the second research question by highlighting the numerous opportunities for participants to exchange ideas and perspectives with individuals from diverse backgrounds personally and professionally. Aligned with the development process of Intercultural Competence, this finding affirms that this long-term immersion research experience is a unique opportunity to engage students in the on-going intercultural competence development process in various facets of life. The students we interviewed shared that a significant benefit of the international research experience was the opportunity to learn from individuals from diverse backgrounds and to develop relationships with research collaborators across the world.

In addition to the development of science identity, selfefficacy, and competencies, our findings answered the third research question through the summation of our participants' stories, specifically how they perceived this experience as crucial in their actualization of becoming a scientist. Although all of the participants engaged in previous research experiences in the U.S. many of them stated that the ability to conduct research independently and collaboratively with researchers from across the world was unique to their iREU experience and validated their science identity. Several of the participants recounted specific instances in which they came to see themselves as a scientist. For most participants, one such example was the positive interactions and feedback from research advisors and mentors in the U.S. and France. Our findings illustrated how the iREU developed our participants' competence, performance, and recognition through the lens of Science Identity, showing that the competencies, confidence, and self-efficacy developed in an international research experience reinforced their identity as a scientist. Moreover, their actualization as a scientist is seen through their commitment to encouraging and supporting others to pursue their desired STEM careers. Our findings suggest the importance of peers sharing their experiences to promote retention and persistence in STEM fields.

With a general understanding of research in the United States, participants were exposed to science and research conducted through the lens of another culture. As a result, they recognized the value and importance of international research collaboration with researchers worldwide for the advancement of their respective STEM fields. For many of the participants, this international research experience was their first time viewing themselves as contributing members of their STEM field on a global scale. Certainly, their prior research experiences were impactful on their development as scientists, but several of the participants indicated that the independence gained in the lab through their IRE gave them a different level of confidence in their abilities. In sum, our findings illuminate the interplay of each sphere of development supported the participants' foundation of their global scientist development.

\section{Implications for Policy and Practice}

Participants noted the importance of participating in an iREU to their overall development as scientists, specifically highlighting how the financial support was critical to their international experience coming to fruition. One student mentioned the financial commitment might be a deterrent for some students with dire financial situations. It is vital to consider how to provide iREU opportunities to STEM students with challenging financial situations.

This study also has important implications for STEM faculty and institutions. Based on our participants' accounts, their iREU experience proves to be a worthy investment for advancing their careers and contributions to their respective STEM fields. With the National Science Foundation's continued support, more STEM faculty should consider developing more iREU program opportunities across various STEM disciplines. It is valuable for colleges and universities to integrate international research opportunities within academic curriculums as unique learning experiences that can cultivate students' science identity and goals while boosting their appeal for the job market after graduation.

While our study focused on the international research experience, it is relevant to note that all participants were actively involved in the LSAMP program. Several of the students shared how their participation in LSAMP exposed them to many beneficial opportunities like iREUs. However, one student shared that the benefits and magnitude of international research experiences could be better explained from the program. As the LSAMP program continues to expose students to iREUs, it is exceedingly critical to detail the benefits of participating in international research experiences for students to grasp the magnitude of this opportunity. 


\section{Future Research and Conclusion}

While we could not explore their nuanced experience in this paper, two women in the study shared instances where they felt challenged based on their gender. Also, several participants mentioned the lack of representation of women advisors in their experiences. Therefore, future research will explore the experiences of women in STEM participating in international research. For example, a similar research study could examine the experiences of women in STEM fields traditionally dominated by men. The opportunity to explore their experiences could provide insights into how they combat gendered stereotypes regarding women in STEM in an international setting.

The current study brings to light the substantial benefits of international research experiences on the science identity, confidence, and competencies of minority students pursuing STEM careers. Although the findings are not representative of all iREU programs, our study adds significant insights to this literature area. For our participants, we find that this experience was a lifechanging opportunity that has broadened their understanding of research on a global scale and affirmed their stance on their capability within their STEM fields. Future research in this area could track the progress of the iREU participants over a period of time. A longitudinal study of participants could illuminate the longterm benefits of an iREU to its participants' career trajectory.

\section{DATA AVAILABILITY STATEMENT}

The raw data supporting the conclusion of this article will be made available by the authors, without undue reservation.

\section{ETHICS STATEMENT}

The studies involving human participants were reviewed and approved by the LSU Institutional Review Board (IRBAM-20-

\section{REFERENCES}

Bangera, G., and Brownell, S. E. (2014). Course-Based Undergraduate Research Experiences Can Make Scientific Research More Inclusive. Life. Sci. Edu. 13, 602-606. doi:10.1187/cbe.14-06-0099

Brownell, J. E., and Swaner, L. E. (2010). Five High-Impact Practices: Research on Learning Outcomes, Completion and Quality. Washington, DC: Association of American Colleges and Universities. doi:10.1016/ j.heares.2009.12.008

Byars-Winston, A. M., Branchaw, J., Pfund, C., Leverett, P., and Newton, J. (2015). Culturally Diverse Undergraduate Researchers' Academic Outcomes and Perceptions of Their Research Mentoring Relationships. Int. J. Sci. Edu. 37, 2533-2554. doi:10.1080/09500693.2015.1085133

Byars-Winston, A., Rogers, J., Branchaw, J., Pribbenow, C., Hanke, R., and Pfund, C. (2016). New Measures Assessing Predictors of Academic Persistence for Historically Underrepresented Racial/Ethnic Undergraduates in Science. Life. Sci. Edu. 15, ar32. doi:10.1187/cbe.16-01-0030

Carlone, H. B., and Johnson, A. (2007). Understanding the Science Experiences of Successful Women of Color: Science Identity as an Analytic Lens. J. Res. Sci. Teach. 44, 1187-1218. doi:10.1002/tea.20237

Chemers, M. M., Zurbriggen, E. L., Syed, M., Goza, B. K., and Bearman, S. (2011). The Role of Efficacy and Identity in Science Career Commitment Among
058801). The participants provided their verbal informed consent to participate in this study.

\section{AUTHOR CONTRIBUTION}

$\mathrm{ZW}-\mathrm{K}$ and $\mathrm{RD}$, equally conceptualized the research study with insights from DS. RD conducted the research study and serves as first author of the article. She, along with $\mathrm{ZW}-\mathrm{K}$, contributed to the organization of the manuscript. All authors contributed to writing sections of the manuscript and editing of the article. All authors have read and approved the submitted version.

\section{FUNDING}

This work was supported by the National Science Foundation Awards (\#1560390), (\#1263336), (\#1826824), and (\#1826738).

\section{ACKNOWLEDGMENTS}

The authors would like to acknowledge Randolph (Randy) S. Duran for his leadership of international research experiences and mentorship of others in developing these learning experiences for students and colleagues. We also thank colleagues such as Emmanuel Gras who supported students while abroad.

\section{SUPPLEMENTARY MATERIAL}

The Supplementary Material for this article can be found online at: https://www.frontiersin.org/articles/10.3389/feduc.2021.674673/ full\#supplementary-material

Underrepresented Minority Students. J. Soc. Issues 67, 469-491. doi:10.1111/ j.1540-4560.2011.01710.x

Crawford, M. B., Wilson-Kennedy, Z. S., Thomas, G. A., Gilman, S. D., and Warner, I. M. (2018). LA-STEM Research Scholars Program: A Model for Broadening Diversity in STEM Education. Technol. Innov. 19 (3), 577-592. doi:10.21300/19.3.2018.577

Daniels, H., Grineski, S. E., Collins, T. W., Morales, D. X., Morera, O., and Echegoyen, L. (2016). Factors Influencing Student Gains from Undergraduate Research Experiences at a Hispanic-Serving Institution. Life. Sci. Edu. 15 (3), ar30. doi:10.1187/cbe.15-07-0163

Davidson, K., Chasten, V. D., Pinder, T., Wellman, S., Byrd, G., Wilson-Kennedy, Z. S., et al. (2018). Analysis of Footwear Co-polymer Compositions by FTIR Spectroscopy and Principal Component Analysis: Sophomore Immersion Program in Research and Academics Program. The Chem. Educator 23, 149-157.

Deardorff, D. K. (2006). Identification and Assessment of Intercultural Competence as a Student Outcome of Internationalization. J. Stud. Int. Edu. 10, 241-266. doi:10.1177/1028315306287002

Deardorff, D. K. (2009). The Sage Handbook of Intercultural Competence. Thousand Oaks, CA: Sage Publications, 477-491.

DeGraaf, D., Slagter, C., Larsen, K., and Ditta, E. (2013). The Long-Term Personal and Professional Impacts of Participating in Study Abroad Programs. Frontiers 23, 42-59. doi:10.36366/frontiers.v23i1.328 
Delauder, S. F., and Holmes, G. P. (2012). Embracing Innovation and Broadening Student Engagement for STEM Majors. Peer Review 14, 18.

Duran, R., Spivak, D., and Satake, A. (2018). "Strengthening a Global LSAMP Research Workforce in France: The NSF LSAMP/Chemistry International REU," in LSAMP: A Program Modeling Group Impact. Editor A. Hicks (Arlington, VA: National Science Foundation).

Dwyer, M. M., and Peters, C. K. (2004). The Benefits of Study Abroad. Transitions abroad 37, 56-58.

Engel, L. (2017). Underrepresented Students and Study Abroad. Available at: https://www.iie.org/Research-and-Insights/Publications/UnderrepresentedStudents-and-Study-Abroad (Accessed February 8, 2021). doi:10.4324/ 9781351147927

Fakayode, S., Byrd, G., Wellman, S., Pinder, T., and Wilson, Z. (2018). "Promoting Undergraduate Research at an HBCU: Sophomore Immersion in Research and Academics Program," in Abstracts of Papers of the American Chemical Society: Amer Chemical SOC 1155 16TH S.T. (WASHINGTON, DC 20036 USA: N.W.).

Fakayode, S. O., Snipes, V., Kanipes, M. I., Mohammed, A. K., and Wilson, Z. S. (2016). "Use of Innovative Pedagogies and Creative Partnership Strategies to Promote Undergraduate STEM Education at an HBCU," in Setting a New Agenda for Student Engagement and Retention in Historically Black Colleges and Universities (Hershey, Pennsylvania: IGI Global), 119-151. doi:10.4018/978-1-5225-0308-8.ch008

Finley, A., and McNair, T. (2013). Assessing Underserved Students' Engagement in High-Impact Practices, Washington, DC: Association of American Colleges.

Green, B. F., Johansson, I., Rosser, M., Tengnah, C., and Segrott, J. (2008). Studying Abroad: A Multiple Case Study of Nursing Students' International Experiences. Nurse Edu. Today 28, 981-992. doi:10.1016/j.nedt.2008.06.003

Haeger, H., and Fresquez, C. (2016). Mentoring for Inclusion: The Impact of Mentoring on Undergraduate Researchers in the Sciences. Life. Sci. Med. 15 (3), ar36. doi:10.1187/cbe.16-01-0016

Hurtado, S., Cabrera, N. L., Lin, M. H., Arellano, L., and Espinosa, L. L. (2009). Diversifying Science: Underrepresented Student Experiences in Structured Research Programs. Res. High Educ. 50, 189-214. doi:10.1007/s11162-008-9114-7

Khan, C. (2020). The State of U.S. Science and Engineering: Science \& Engineering Indicators. National Center for Science And Engineering Statistics. Available at: https://ncses.nsf.gov/pubs/nsb20201 (Accessed February 8, 2021). doi:10.1109/ aset 48392.2020 .9118352

Kuh, G. D. (2008). High-Impact Educational Practices: What They Are, Who Has Access to Them, and Why They Matter. Washington, DC: Association of American Colleges and Universities.

Kuh, G. D., Kinzie, J., Schuh, J. H., and Whitt, E. J. (2010). Student success in College: Creating Conditions that Matter. Malden, MA: John Wiley \& Sons.

Lincoln, Y. S., and Guba, E. G. (1985). Establishing Trustworthiness. Naturalistic Inq. 289, 289-327.

Merriam, S. B., and Tisdell, E. J. (2015). Qualitative Research: A Guide to Design and Implementation. Malden, MA: John Wiley \& Sons.

Miles, M. B., and Huberman, A. M. (1994). Qualitative Data Analysis: An Expanded Sourcebook. Thousand Oaks, CA: Sage publications.

Murphy, D., Sahakyan, N., Yong-Yi, D., and Magnan, S. S. (2014). The Impact of Study Abroad on the Global Engagement of University Graduates. Frontiers 24, 1-24. doi:10.36366/frontiers.v24i1.333

National Academies of Sciences Engineering and Medicine (NASEM) (2016). Barriers and Opportunities for 2-Year and 4-Year STEM Degrees: Systemic Change to Support Students \& Diverse Pathways. Washington, DC: The National Academies Press.
National Science Foundation (2019). "Employed Scientists and Engineers, by Sector of Employment, Broad Occupation, Sex, Ethnicity, Race, and Disability Status: 2017 (Table 9-19)," in Women, Minorities, and Persons with Disabilities in Science and Engineering (Alexandria, VA: National Center for Science and Engineering Statistics).

National Science Foundation (2020). Louis Stokes Alliances for Minority Participation (LSAMP). Available at: https://www.nsf.gov/funding/pgm_ summ.jsp?pims_id=13646.

O’Donnell, K., Botelho, J., Brown, J., González, G. M., and Head, W. (2015). Undergraduate Research and its Impact on Student Success for Underrepresented Students. New Dir. Higher Edu. 2015, 27-38. doi:10.1002/ he. 20120

Owens, B. (2018). The Benefits and Challenges of International Research Collaboration. Available at: https://www.universityaffairs.ca/features/featurearticle/the-benefits-and-challenges-of-international-research-collaboration/ (Accessed February 8, 2021). doi:10.4324/9781315809748

Pender, M., Marcotte, D. E., Sto. Domingo, M. R., and Maton, K. I. (2010). The STEM Pipeline: The Role of Summer Research Experience in Minority Students' Graduate Aspirations. epaa 18, 30. doi:10.14507/epaa.v18n30.2010Domingo

Salisbury, M. H., An, B. P., and Pascarella, E. T. (2013). The Effect of Study Abroad on Intercultural Competence Among Undergraduate College Students. J. Student Aff. Res. Pract. 50, 1-20. doi:10.1515/jsarp-2013-0001

Sanchez, G. J. (2012). Intensive Study Abroad For First-Generation College Students. Peer Review 14, 14

Stake, R. E. (1995). The Art of Case Study Research. Thousand Oaks, CA: Sage.

Stebleton, M. J., Soria, K. M., and Cherney, B. T. (2013). The High Impact of Education Abroad: College Students' Engagement in International Experiences and the Development of Intercultural Competencies. Frontiers 22, 1-24. doi:10.36366/frontiers.v22i1.316

Strauss, A., and Corbin, J. (1998). Basics of Qualitative Research Techniques. Thousand Oaks, CA: Sage publications.

Wilson, Z. S., Holmes, L., deGravelles, K., Sylvain, M. R., Batiste, L., Johnson, M., et al. (2012). Hierarchical Mentoring: a Transformative Strategy for Improving Diversity and Retention in Undergraduate Stem Disciplines. J. Sci. Educ. Technol. 21 (1), 148-156. doi:10.1007/s10956-011-9292-5

Yin, R. K. (2017). Case Study Research and Applications: Design and Methods. Dallas, TX: Sage publications.

Yin, R. K. (2014). Case Study Research: Design and Methods. 5th ed. Dallas, TX: Sage publications.

Z.S. Wilson-Kennedy, G.S. Byrd, E. Kennedy, and H.T. Frierson (2019). Broadening Participation in STEM: Effective Methods, Practices, and Program (West Yorkshire, UK: Emerald Publishing Limited).

Conflict of Interest: The authors declare that the research was conducted in the absence of any commercial or financial relationships that could be construed as a potential conflict of interest.

Copyright $\odot 2021$ Davis, Wilson-Kennedy and Spivak. This is an open-access article distributed under the terms of the Creative Commons Attribution License (CC BY). The use, distribution or reproduction in other forums is permitted, provided the original author(s) and the copyright owner(s) are credited and that the original publication in this journal is cited, in accordance with accepted academic practice. No use, distribution or reproduction is permitted which does not comply with these terms. 